\title{
Ordenamento Legal de Esporte e Lazer na Cidade de Salvador: uma década de leis (2006-2016)
}

\author{
Legal Ordinance of Sports and Leisure in the City of Salvador: A decade of laws (2006-2016) \\ Ordenanza legal de Deporte y Ocio en la Ciudad de Salvador: una década de leyes (2006-2016)
}

\author{
Hosana Larissa Guimaräes Oliveira \\ Câmara Municipal de Salvador, Brasil \\ larissa_guimaraes@yahoo.com.br \\ iD https://orcid.org/0000-0001-6120-7003
}

Augusto Cesar Rios Leiro
Universidade Federal da Babia, Brasil
cesarleirocbce@gmail.com

(D) https://orcid.org/0000-0002-6075-5187

\author{
Priscila Costa do Nascimento \\ Faculdade Social da Babia, Brasil \\ priscilanche@hotmail.com
}

\section{Resumo:}

Este artigo tem como objetivo analisar as leis que regulamentam o esporte e lazer na cidade de Salvador, publicadas entre 2006 e 2016, enquanto aparatos legais que regem o exercício de cidadania. Para tanto, foi realizada uma pesquisa de natureza qualitativa, do tipo documental, que teve como base de informações o governo eletrônico da Câmara Municipal de Salvador. Foram levantadas 13 leis, que foram classificadas nas seguintes categorias: 1) desenvolvimento e organização da cidade; 2) estrutura organizacional da gestão municipal; 3) grandes eventos; 4) data comemorativa; e 5) esporte educacional. A análise das leis indica que há limitações na legislação pesquisada, por serem ora generalistas, ora pontuais, assim como, é necessária uma maior difusão do conhecimento sobre essas leis, para que a população possa fiscalizar e participar do processo de construção das políticas públicas de esporte e lazer da cidade, desde a sua elaboração até a sua implementação em ações concretas para o cidadão soteropolitano.

PalaVRas-ChaVe: Esporte, Lazer, Ordenamento legal, Legislação municipal.

\begin{abstract}
:
This article aims to analyze the laws that regulate sport and leisure in the city of Salvador, published between 2006 and 2016 , as legal devices that regulating the exercise of citizenship. For this purpose, a qualitative research was carried out, of the documentary type, that was based on information from the e-government of the City Hall of Salvador. 13 laws were found, which were classified in the following categories: 1) development and organization of the city; 2) organizational structure of municipal management; 3) great events; 4) commemorative date; and 5) educational sport. The analysis of the laws indicates that there are limitations in the legislation being researched, because they are sometimes generalist or punctual, as well as a greater diffusion of the knowledge about these laws, so that the population can supervise and participate in the process of construction of public policies sports and leisure, from its elaboration until its implementation in concrete actions for the Soteropolitan citizen.
\end{abstract}

KEYWORDS: Sport, Leisure, Legal ordering, Municipal legislation, Introdução.

\section{Resumen:}

Este artículo tiene como objetivo analizar las leyes que regulan el deporte y el ocio en la ciudad de Salvador, publicadas entre 2006 y 2016, entendidas como aparatos legales que rigen el ejercicio de la ciudadanía. Para ello se realizó una investigación cualitativa, de tipo documental, basada en el gobierno electrónico del Ayuntamiento de Salvador. Se encontraron 
13 leyes, las cuales se clasificaron en las siguientes categorías: 1) desarrollo Āorganización de la ciudad; 2) estructura organizativa gestión municipal; 3) grandes eventos; 4) fecha conmemorativa; y 5) deporte educativo. El análisis de las leyes indica que existen limitaciones en la legislación investigada, ya que a veces son generalistas, a veces puntuales, así como es necesaria una mayor difusión del conocimiento sobre estas leyes, para que la población pueda monitorear y participar en el proceso de construcción de políticas públicas de deporte y ocio en la ciudad, desde su creación hasta su implementación en acciones concretas para el ciudadano salvadoreño.

Palabras ClaVe: Desporte, Ocio, Ordenanza legal, Legislación municipal.

\section{INTRODUÇÃo}

Ao ingressar na temática do ordenamento legal de esporte e lazer, toma-se o desafio de colaborar com uma demanda ainda pouco explorada entre as publicações que trazem o esporte e o lazer como objeto de estudo. Dessa forma, o artigo trata da legislação que regulamenta e direciona a gestão do esporte e o lazer $\mathrm{Na}$ em Salvador.Constituição da República Federativa do Brasil (1988), na Constituição do Estado da Bahia e na Lei Orgânica da Cidade do Salvador o esporte e o lazer são considerados direitos que devem ser garantidos pelo Estado. Para tanto, o poder público deve se empenhar para garantir as políticas públicas de esporte e lazer, que incluem, dentre outras ações, do ponto de vista do legislativo: a criação de leis que regulamentem tais políticas e a fiscalização das ações nesse âmbito; do ponto de vista do executivo: a destinação de recursos públicos para este fim, a construção e manutenção de espaços e equipamentos públicos de esporte e lazer, a implementação de programas e projetos de desenvolvimento de culturas corporais e lazer.

Contudo, no contexto da globalização, o esporte e o lazer vêm sendo tratado, hegemonicamente, como produtos, em boa parte, por terem se tornado objeto de comércio da indústria do entretenimento e da cultura de massa, tornando-se aquilo que Mascarenhas (2005) chama de "mercolazer". Para o referido autor, soa como fantasia o lazer gratuito, pois, para ser garantido como direito de todos, há necessidade de se transformar primeiro o modelo de sociedade em que vivemos, tornando-a mais igualitária para aqueles que vivem nela. Nesse sentido, Mascarenhas (2005) defende a "lazerania", conceito que compreende tais direitos como exercício de cidadania, composto por elementos como a autonomia, a participação e a democracia, deixando de ser usufruído apenas por aqueles que podem pagar pelo acesso ao esporte e lazer.

Portanto, ao considerar que o esporte e o lazer são direitos constitucionais e deveres do Estado, que se concretizam na cidade e no contexto de contradições da sociedade capitalista, interessou, neste artigo, saber qual a legislação municipal que respalda esses direitos à população soteropolitana.

Dessa forma, tem-se como objetivo analisar as leis que regulamentam o esporte e o lazer da cidade de Salvador publicadas entre 2006 e 2016, através da discussão do ordenamento legal nacional e citadino, como aparatos legais que regulamentam exercício de cidadania.

A escrita foi organizada em cinco seções, sendo esta a que se refere à introdução com indicação da problemática e do objetivo da pesquisa. A segunda seção traz os caminhos metodológicos trilhados nessa investigação. A terceira faz uma contextualização da legislação do esporte e do lazer no cenário nacional. A discussão das leis que regulamentam o esporte e o lazer em Salvador, no recorte temporal entre 2006 e 2016, é apresentada na quarta seção. Na quinta, por fim, são tecidas as considerações finais deste estudo.

\section{Trilhas METODOLÓGICAS}

Este trabalho tem natureza qualitativa com base nos estudos de Minayo (2001) e se caracteriza como pesquisa documental, que, segundo Gil (2008), se diferencia da pesquisa bibliográfica pela origem das fontes: enquanto na primeira utiliza-se a fonte primária, pesquisando o documento em si, na segunda, valese da contribuição de outros autores que já estudaram a temática em questão. Os registros levantados foram os institucionais escritos, neste caso específico, as leis municipais.

A base de informações para essa investigação foi o Governo eletrônico (e-Gov) da Câmara Municipal de Salvador ${ }^{1}$, que disponibiliza todas as leis publicadas em âmbito municipal. Segundo Oliveira e Leiro 
(2016), e-Gov são "documentos dinâmicos e plataformas eletrônicas potenciais de difusão formal dos deveres do Estado, direitos sociais e controle democrático. É espaço/tempo contemporâneo capaz de promover a interação entre cidadãos e governos públicos" (p. 541).

Para os autores, são a forma de comunicação, através da tecnologia da informação, mais rápida e prática entre o governo e a população. Por isso, o e-Gov foi eleito nesta pesquisa como fonte legítima para pesquisa documental.

Considerando tal conceito, o estudo teve início com a busca das leis que regulamentam o esporte e o lazer na cidade de Salvador, publicadas entre os anos de 2006 e 2016, somando uma década de leis. Tal recorte temporal tomou como referência a realização dos Jogos Olímpicos de 2016, sediados também na capital baiana, cujo levantamento documental foi realizado a partir da trajetória decrescente das leis instituídas por uma década. Foram utilizados os descritores: "esporte", que resultou em 804 documentos, e "lazer", que remeteu a 163 documentos. Após esse primeiro levantamento, foi utilizado um filtro que considerou como critério de inclusão para os documentos: ser lei, ter sido publicado entre 2006 e 2016 e referir-se à regulamentação do esporte e do lazer em Salvador. Dessa forma, foram consideradas 13 leis sobre o esporte e o lazer na cidade para estudo.

Foi utilizada a análise de conteúdo temática (Minayo, 2001), com organização das leis em cinco categorias, que emergiram no tratamento dos dados: 1) desenvolvimento e organização da cidade; 2) estrutura organizacional da gestão municipal; 3) grandes eventos; 4) data comemorativa; e 5) esporte educacional. A partir dessas categorias, as leis foram discutidas como aparatos legais que regulamentam o direito ao esporte e do lazer em Salvador.

Antes de entrar na discussão específica da legislação municipal, cabe trazer uma breve contextualização do ordenamento legal de esporte e o lazer em cenário nacional e os conceitos de referência dessa investigação.

\section{LAZER E ESPORTE PELA LENTE DA LEGISLAÇÃO}

$\mathrm{Na}$ Carta Magna brasileira (1988), o lazer é citado em quatro momentos: ao ser afirmado como direito social; quando se refere ao salário mínimo do trabalhador, que deve assegurar-lhe dentre outros direitos, o lazer; quanto à obrigação do poder público de incentivá-lo como forma de promoção social, incentivando o desenvolvimento de todo cidadão; e no reforço da absoluta prioridade a uma série de direitos para a criança, o adolescente e o jovem, que incluem o lazer. Dessa forma, sendo este um direito social, dentro dos direitos e garantias fundamentais do cidadão brasileiro, deve ser um dos elementos basilares para a constituição de uma vida mais digna ao soteropolitano.

Segundo Marcellino (2007b), o lazer é composto por três fundamentos: 1) a atitude, fruto da relação entre o sujeito e a experiência vivida, que é a busca da satisfação ou bem-estar causado pela prática de tal atividade e é algo bastante pessoal e variável com as experiências de cada um;2) o tempo disponível é outro integrante do lazer, que se constitui no momento em que a pessoa está liberada das suas obrigações relacionadas ao trabalho, à família, à religião, dentre outras; e 3) a ação, pois o conteúdo isolado não determina a conceituação, já que, a mesma atividade pode ser de lazer ou profissional. Portanto, para saber se uma atividade é lazer, é preciso avaliá-la a partir da relação entre atitude, tempo e ação envolvidos.

Outro aspecto a ser considerado quando se pensa em lazer é a sua relação com o trabalho, já que alguns equívocos vêm sendo disseminados diante do contexto de supervalorização do trabalho, próprio da sociedade capitalista, e precisam ser combatidos e/ou contestados. Para Melo e Alves Jr. (2012), entre os equívocos estão: o lazer seria menos importante que o trabalho; numa suposta hierarquia de necessidades humanas, o lazer ficaria depois da educação e saúde, por exemplo; seria um momento de não fazer nada ou fuga da realidade; sua finalidade principal seria a recuperação das forças para o trabalho.

A superação desses preconceitos sobre o lazer requer a apropriação e a compreensão deste enquanto: "um fenômeno tipicamente moderno, resultante das tensões entre capital e trabalho, que se materializa 
como um tempo e espaço de vivências lúdicas, lugar de organização da cultura, perpassado por relações de hegemonia" (Mascarenhas, 2001, p. 92).

Para tanto, é essencial tomá-lo em sua especificidade concreta, que inclui, conforme Marcellino (2007a), o seu entendimento de forma ampla em relação ao conteúdo, as atitudes que estão envolvidas, os valores que irão propiciar, reconhecer duplo aspecto educativo como veículo e objeto de educação, as suas potencialidades como instrumento de mobilização social e de participação cultural, além de verificar as barreiras socioculturais que impedem a sua efetivação, tanto intraclasses quanto interclasses sociais.

Após apresentada essas considerações iniciais sobre o lazer, cabe agora trazer os referenciais que embasam esta pesquisa em relação ao esporte.

Bracht (2011) destaca o esporte nas perspectivas de lazer e de espetáculo - transformado-o em mercadoria. O primeiro possui características do segundo, assim como há propriedades que os divergem. Para ele, o esporte é dividido entre aquele praticado no momento de lazer, sem regras rígidas e sem a busca da melhor performance, na expectativa de ter prazer na atividade e adquirir a cultura da modalidade que se escolheu praticar. A outra prática é a do esporte espetáculo que tem como objetivo alcançar cada vez mais as melhores marcas, o tempo não é livre ou disponível, mas está ligado ao alcance de metas. Os dois modelos também são considerados como lazer, no que tange à função social, já que o esporte de rendimento será o espetáculo consumido no tempo de lazer e, na maioria das vezes, com alto custo para seu acesso. Assim, por vezes, o esporte será lazer para quem assiste; em outras, será na prática em si.

A Lei n. ${ }^{0} 9.615$ (1998), conhecida como Lei Pelé, regulamenta o esporte em nosso país sob variados aspectos. Ela categoriza o esporte em formal, regulado por normas nacionais e internacionais de cada modalidade, e não formal, caracterizado pela liberdade e ludicidade na sua prática. Classifica-o ainda em esporte educacional: como sendo aquele que se concretiza nos sistemas de ensino e visa o desenvolvimento integral do participante, sua formação para a cidadania e para o lazer; em esporte de participação: como o esporte praticado em momentos de lazer, com o objetivo de integrar seus participantes, auxiliar na melhoria da saúde, educação e preservação do meio ambiente; esporte de rendimento: forma desportiva praticada sob regras de prática nacional e internacional, almejando obter resultados; e, por último, o esporte de formação: que se caracteriza pelo interesse da aquisição inicial dos conhecimentos técnicos desportivos.

A abordagem do esporte enquanto fenômeno social é trazida por Leiro et al (2010) quando discutem como essas dimensões do esporte passaram a determinar a forma de distribuição dos recursos destinados ao esporte no Brasil, influenciando na estrutura organizacional da pasta em nível federal.

Na própria Lei Pelé, há determinação da destinação dos recursos do Ministério do Esporte ${ }^{2}$, que deve priorizar primeiro o esporte educacional, em seguida, o esporte de rendimento em competições internacionais, o esporte de criação nacional e a capacitação dos profissionais envolvidos com ele, a construção e reparação de instalações desportivas, apoio à assistência ao atleta profissional para se adaptar ao mercado de trabalho após deixar a atividade e apoio ao esporte para pessoas com deficiência.

Outro ponto importante a se considerar em cenário nacional é a Política Nacional do Esporte, que surge em 2005, e é outro instrumento importante no que se refere à regulamentação do esporte e do lazer no país. Foi resultado de um longo debate em todo o Brasil, pois foi tema da I Conferência Nacional do Esporte, em 2004. Essa política tem foco na inclusão social e tem o esporte e o lazer como importantes fatores de promoção de saúde, acreditando que a atividade física deve fazer parte do cotidiano de todos (Ministério do Esporte, 2005). Tem como objetivos:

Democratizar e universalizar o acesso ao esporte e ao lazer, na perspectiva da melhoria da qualidade de vida da população brasileira; promover a construção e o fortalecimento da cidadania assegurando o acesso às práticas esportivas e ao conhecimento científico-tecnológico a elas inerente; descentralizar a gestão das políticas públicas de esporte e de lazer; fomentar a prática do esporte de caráter educativo e participativo, para toda a população, além de fortalecer a identidade cultural esportiva a partir de políticas e ações integradas com outros segmentos; incentivar o desenvolvimento de talentos esportivos em potencial e aprimorar o desempenho de atletas e paraatletas de alto-rendimento, promovendo a democratização dessa manifestação esportiva (Ministério do Esporte, 2005, p.32). 
Há ainda a esperança de mais uma vez ratificar o que a Constituição Federal e a Lei n. ${ }^{\circ} 9.615$ (1998) já haviam citado, sempre com o intuito de garantir o acesso ao esporte e ao lazer. É nessa perspectiva que deve seguir o ordenamento legal dos estados e municípios.

A Política em questão tem como princípios fomentar a equidade social, o esporte e o lazer como direito de todos e dever do Estado, a propagação e a inclusão social e, por último, a ampla participação na gestão, que dá direito aos interessados em participar da construção dos documentos que normatizam o esporte e o lazer, já que são seus beneficiários diretos ou indiretos (Ministério do Esporte, 2005).

Discutido alguns instrumentos legais em contexto nacional, a seguir será apresentada a análise da legislação do esporte e do lazer em Salvador.

\section{EsPorTe E LAZER EM SALVADOR: ANÁLISE DE UMA DÉCADA DE LEIS (2006-2016)}

Como no Brasil "ninguém será obrigado a fazer ou deixar de fazer alguma coisa senão em virtude de lei” (BRASIL, 1988), destacaremos nesta seção a legislação de esporte e o lazer da cidade de Salvador, como aparatos legais que regulamentam exercício de cidadania dos cidadãos soteropolitanos.

A análise da legislação nesta seção acontecerá a partir da sua organização em torno das cinco categorias já referidas nas trilhas metodológica deste estudo e a classificação das 13 leis levantadas, que se encontram expressas no Quadro 1, como segue: 
QUADRO 1 - Leis referentes ao esporte e lazer na cidade de Salvador, publicadas entre 2006 e 2016

\begin{tabular}{|c|c|c|}
\hline $\begin{array}{l}\text { CATEGORIA } \\
\text { TEMA }\end{array}$ & N.\%ANO & EMENT A \\
\hline \multirow{2}{*}{$\begin{array}{l}1 \\
\text { Desenvolvimento e } \\
\text { organização da } \\
\text { cidade }\end{array}$} & $9.069 / 2016$ & $\begin{array}{l}\text { Dispõe sobre o Plano Diretor de Desenvolvimento Urbano } \\
\text { (PDDU) de } 2016 \text { do município de salvador e dá outras } \\
\text { providências. }\end{array}$ \\
\hline & $9.148 / 2016$ & $\begin{array}{l}\text { Dispõe sobre o ordenamento do uso e da ocupação do solo } \\
\text { do município de salvador e dá outras providências. }\end{array}$ \\
\hline \multirow{4}{*}{$\begin{array}{l}\qquad 2 \\
\text { Estrutura } \\
\text { organizacional da } \\
\text { gestão municipal }\end{array}$} & $7.650 / 2009$ & $\begin{array}{l}\text { Altera a denominação da Secretaria Municipal da Educação } \\
\text { e Cultura (SMEC) para Secretaria Municipal da Educação, } \\
\text { Cultura, Esporte e Lazer (Secult), modifica a sua estrutura } \\
\text { organizacional e dá outras providências. }\end{array}$ \\
\hline & $8.376 / 2012$ & $\begin{array}{l}\text { Modifica a estrutura organizacional da Prefeitura Municipal } \\
\text { de Salvador (PMS) e dá outras providências. }\end{array}$ \\
\hline & $8.725 / 2014$ & $\begin{array}{l}\text { Modifica a estrutura organizacional da PMS e dá outras } \\
\text { providências. }\end{array}$ \\
\hline & $9.186 / 2016$ & $\begin{array}{l}\text { Modifica a estrutura organizacional da PMS e dá outras } \\
\text { providências. }\end{array}$ \\
\hline \multirow{3}{*}{$\begin{array}{c}3 \\
\text { Grandes eventos }\end{array}$} & $7.720 / 2009$ & $\begin{array}{l}\text { Dispõe sobre medidas a serem adotadas pelo município do } \\
\text { Salvador para a realização de competições relativas aos } \\
\text { Jogos Olímpicos e Paraolímpicos de } 2016 \text { e dá outras } \\
\text { providências. }\end{array}$ \\
\hline & $7.721 / 2009$ & $\begin{array}{l}\text { Concede isenção, por tempo determinado, dos tributos } \\
\text { municipais à Federação Internacional de Futebol } \\
\text { Associação (FIFA) e às entidades vinculadas à organização } \\
\text { e à realização da Copa Mundial da FIFA de 2014, } \\
\text { relativamente aos serviços, patrimônio e operações } \\
\text { diretamente afetados a esta finalidade. }\end{array}$ \\
\hline & $9.089 / 2016$ & $\begin{array}{l}\text { Altera e acrescenta dispositivos à Lei } n^{\circ}{ }^{\circ} 7.720 / 2009 \text { (Ato } \\
\text { Olímpico Municipal) e dá outras providências. }\end{array}$ \\
\hline $\begin{array}{c}4 \\
\text { Data comemorativa }\end{array}$ & $8.838 / 2015$ & $\begin{array}{l}\text { Institui o dia } 1^{\circ} \text { de Outubro como o "dia municipal de } \\
\text { esporte para a pessoa idosa". }\end{array}$ \\
\hline \multirow{2}{*}{$\begin{array}{c}5 \\
\text { Esporte educacional }\end{array}$} & $7.045 / 2006$ & $\begin{array}{l}\text { Dispõe sobre a criação de programa de atividades } \\
\text { desportivas no âmbito dos estabelecimentos de ensino, no } \\
\text { período de férias escolares. }\end{array}$ \\
\hline & $7.656 / 2009$ & $\begin{array}{l}\text { Estabelece normas para atuação do professor de Educação } \\
\text { Física no município de Salvador. }\end{array}$ \\
\hline
\end{tabular}


$\mathrm{Na}$ categoria "Desenvolvimento e organização da cidade" serão discutidas leis que regulamentam o desenvolvimento urbano de Salvador. Têm-se o Plano Diretor de Desenvolvimento Urbano (PDDU) regulamentado pela Lei n. ${ }^{9} 9.069$ (2016), que traz um capítulo específico para tratar "Do lazer, recreação e esportes". Em seu art. 108, são apontadas as diretrizes para a extensão dos meios de acesso ao lazer e ao esporte, em especial às áreas periféricas, com redistribuição espacial dos equipamentos públicos e ampliação da diversificação da oferta, mediante criação de espaços multifuncionais para as atividades de esporte, recreação e lazer. Também são citados o estímulo para os esportes náuticos, a integração do esporte na estratégia econômica de Salvador e a inclusão de atividades desportivas para pessoas com deficiência nas escolas. Merece destaque também o incentivo à democratização a partir do estabelecimento de condições para o funcionamento do Conselho Municipal de Esporte e Lazer e a implementação de planejamento e orçamento para o setor (Lei n. ${ }^{\circ}$ 9.069, 2016).

Como é dever do Estado garantir os direitos do cidadão, e sendo o esporte e lazer parte deles, na construção do instrumento que regula o desenvolvimento da cidade, eles se fazem presentes em alguns momentos, pois é no espaço citadino que se concretizam:

Nos espaços públicos de Esporte e lazer observamos práticas corporais urbanas e estes nos possibilitam uma investigação das relações que ali se estabelecem. Tais relações oportunizam entre outras coisas a sociabilidade, a prática esportiva, a atividade física, a brincadeira, o desenvolvimento cultural, assim como os confrontos, embates e tensões sociais que podem surgir na produção dessas experiências (Tschoke, 2013, p. 2).

Considera-se assim que os espaços e equipamentos públicos que são destinados à prática de esporte e lazer na cidade são fundamentais para potencializá-los como espaço/tempo de mobilização social e de participação cultural, isto, quando são planejados para e junto à população que irá usufruir desses espaços, numa constituição de políticas públicas democráticas e construídas na participação cidadã.

Já a Lei de Ordenamento do Uso e da Ocupação do Solo (Louos) - Lei n. 9.148 (2016) - descreve detalhadamente onde e como é permitida a construção de espaços para a prática desportiva e de lazer, assim como disciplina a proporção de áreas destinadas à recreação e ao lazer em solo de uso residencial. A lei também apresenta forte relação entre as áreas verde da cidade como espaços de lazer, fortalecendo a sua relação com o meio ambiente.

Segundo Silva et al (2012), os espaços públicos de lazer têm significado para seus usuários que são resultados dos benefícios causados pelas práticas realizadas nestes. Por isso, Ziperovich (citado em Silva et al., 2012) traz a importância de a infraestrutura estar em conformidade com os interesses da população que faz o uso desses espaços, já que, para Silva et al (2012), “espaços públicos de lazer são lugares de interação humana e mediação social”. Como podemos perceber, é notável a importância da ordenação e adequação do espaço público de esporte e lazer para os que habitam a cidade, a fim de que possa ser povoada e bem utilizada, não se tornando, apenas, mais uma obra incoerente com os anseios da população e que representa unicamente uma intervenção verticalizada do poder público.

$\mathrm{Na}$ categoria "Estrutura organizacional da gestão municipal", estão as proposições relacionadas às mudanças na disposição das pastas municipais, com extinção de secretárias e junção com outras. Esse movimento se dá, notadamente, no início dos mandatos de prefeito, a fim de adequar a gestão à sua plataforma de governo ou ainda para atender interesses específicos e/ou prioridades em pauta.

$\mathrm{Na}$ década analisada, ocorreram três modificações relacionadas à gestão das pastas de esporte e lazer em Salvador: com a Lei n. ${ }^{\circ} 8.376$, de 2012, o esporte e o lazer se tornaram responsabilidade da Secretaria de Educação; em 2014, a pasta foi transferida para a Secretaria Municipal de Promoção Social e Combate à Pobreza (Semps); e, em 2016, passou a integrar a Secretaria Municipal do Trabalho, Esportes e Lazer (Semtel). 
Essas mudanças indicam que o esporte e o lazer sempre compõem as secretarias junto com outros setores. $\mathrm{Na}$ literatura, não há consenso sobre a garantia de eficácia quando se opta por uma estrutura organizacional específica. Quando se trata do lazer, Marcellino (1996) afirma que seu conteúdo é analisado de forma limitada. Por isso, algumas gestões acabam restringindo-o a atividades culturais ou esportivas, esquecendo-se do seu aspecto educativo e alocando-o junto com outras pastas de modo que suas ações são reduzidas. $\mathrm{O}$ autor traz ainda que deve haver inter-relação com as pastas no setor no qual o lazer estiver alocado, assim como com as políticas públicas de educação, saúde e promoção social. Dessa forma, as ações de lazer não se tornam reduzidas, pois devem ser pensadas de forma geral, intersetorial e com previsão de alocação orçamentária para as ações específicas do esporte e do lazer. A intersetorialidade pode potencializar ações em projetos e programas que seriam muito mais proveitosas para a população do que simples atividades de entretenimento, quando se reduz as dimensões sociais, educacionais e culturais do esporte e lazer.

Santos e Starepravo (2018) analisam que, como os investimentos municipais em esporte ainda são uma temática pouco estudada, não é possível ter informações concretas sobre a relação de causalidade entre ter uma secretaria exclusiva e o aumento dos investimentos. Em seus estudos sobre a estrutura político administrativa das prefeituras do Piauí, concluíram que a estrutura organizacional não interferiu diretamente na capacidade citadina de investir no esporte.

De fato, a importância reside em ter o esporte e o lazer na agenda pública, com rubrica garantida nas Leis Orçamentárias da cidade, viabilizando o desenvolvimento de ações relacionadas que não sejam limitadas e pontuais em simples eventos. Além da previsão de recursos próprios no orçamento da cidade, têm-se a possibilidade de fortalecer o financiamento das políticas públicas na área, a partir da criação de um fundo municipal de esporte e lazer. O objetivo desse instrumento é ter recursos financeiros específicos para garantia desses direitos, bem como, para criação e manutenção de conselhos municipais, com intuito de estimular a participação popular no controle da aplicação desses recursos.

A categoria "Grandes eventos" diz respeito à realização de eventos internacionais que aconteceram na cidade de Salvador, organizados pela Federação Internacional de Futebol (FIFA) e pelo Comitê Olímpico Internacional (COI) e respectivos comitês organizadores locais. Para tanto, foram elaboradas leis que suprissem a demanda de tais acontecimentos, por tempo determinado, com relação direta ou indireta na organização dos eventos desportivos.

A Lei n. ${ }^{\circ} 7.720$ (2009), por exemplo, garantia a organização estrutural da cidade para atender aos Jogos Olímpicos que viessem a ser realizados em Salvador, com provimento de estrutura, conforto e segurança aos participantes do evento. Essa é uma lei que tinha a pretensão de manter a ordem na cidade para assegurar o bom andamento das Olimpíadas.

Nessa categoria, encontra-se também a Lei n. ${ }^{\circ} 7.721$ (2009) que permitia a isenção de impostos à FIFA ou qualquer pessoa ou empresa que prestasse serviço relativo à Copa 2014.

Sobre os grandes eventos, Costa (2013) afirma que eles trazem consequências positivas apenas para uma parcela minoritária da população, pois os seus "custos sociais" mais comuns são: o despejo de pessoas para as construções relacionadas ao evento, empregos precários nas construções e no evento em si, a gentrificação e falta de transparência das decisões. Dessa forma, pode-se notar que os megaeventos não são interessantes para boa parte da comunidade que sofre os efeitos negativos a médio e longo prazo, em prol do espetáculo que é realizado para uma porção seleta da população local e turistas.

O autor alerta ainda que os megaeventos, ao contrário do que é posto pela mídia como o auge de um país, na verdade, acarretam grandes danos as seus habitantes. Um deles é o desvio de verbas públicas para grandes construções de infraestrutura urbana e local do evento, que deixam de ser investidos em questóes nas quais a população carece, dentre os quais se encontram o esporte e lazer.

Na categoria "Data comemorativa", encontra-se a Lei n. 8.838 (2015), que se refere à criação do Dia Municipal de Esporte para o Idoso. A data coincide com o Dia Nacional do Idoso, escolhido em homenagem 
à aprovação do Estatuto do Idoso, com o intuito de incentivar a prática desportiva da pessoa idosa, com o devido acompanhamento de professores de educação física e profissionais de saúde. Constando ainda que:

Art. $3^{\circ}$. São objetivos fundamentais do 'Dia Municipal de Esporte para a Pessoa Idosa':

I- estimular e motivar órgãos públicos e privados a promover, realizar e divulgar eventos esportivos que valorizem a pessoa idosa;

II- articular ações de socialização, promoção da cidadania e qualidade de vida aos idosos (Lei nº. 8.838, 2015).

Essa lei pretende inserir a prática desportiva no mundo do idoso, ao considerar que, por meio dela, o sujeito pode prolongar sua qualidade de vida, mesmo com o avanço da idade, levando-o ao processo de senescência que é o envelhecimento saudável (Appell e Meta citado em Depieri, 2000). No entanto, deve-se reconhecer que atividades pontuais apenas em uma data comemorativa não são capazes de alcançar os objetivos indicados.

Vale ressaltar também, que o direito ao esporte para o idoso é uma das premissas expressas no art. $3^{\circ}$ do Estatuto do Idoso brasileiro, a Lei no 10.741(2003), quando se coloca como obrigação da família, da comunidade, da sociedade e do Poder Público assegurar com absoluta prioridade a sua efetivação. Sendo assim, para além de uma data comemorativa o esporte deve ser encarado como exercício de cidadania da pessoa idosa no Brasil.

$\mathrm{Na}$ categoria "Esporte educacional", estão as leis que regulam as atividades esportivas nas escolas, desde a obrigatoriedade da construção de quadras poliesportivas, passando pela exigência de se ter um professor licenciado em Educação Física e a criação de programas desportivos durante as férias. Esses instrumentos legais buscam incentivar o desenvolvimento do esporte no âmbito escolar, garantindo ampla participação, sem discriminação de desempenho, já que trata do esporte como veículo educacional.

A Lei n. ${ }^{\circ} 7.045$ (2006) refere-se à criação de programas desportivos nas férias: “Art. $1^{\circ}$. O Poder Público Municipal estimulará a criação de um programa de atividades desportivas nos estabelecimentos de ensino, no período de férias escolares". Essas atividades podem ser realizadas em clubes, caso não haja espaço adequado na escola, com monitores treinados e de preferência da própria comunidade. Essa é uma lei que fomenta a prática de esportes em momentos em que os alunos, muitas vezes, não têm espaço ou equipamento público disponível para usufruir desse direito.

A Lei n. ${ }^{\circ} 7.656$ (2009) determina que:

Art. $3^{\circ}$. Para ministrar as aulas de educação física o professor deve possuir curso superior completo e Licenciatura Plena em Educação Física, ser portador de habilitação profissional expedida pelo Conselho Regional de Educação Física, observadas as disposições da Lei Federal n 9696/1998.

Refere-se, portanto, a uma condição para atuar como docente nas aulas de educação física em Salvador, indica a quantidade de aulas por semana e especifica a necessidade da formação e da habilitação do professor no Conselho Regional de Educação Física da Bahia (CREF-BA), sujeito a fiscalização pelo órgão.

A própria Lei de Diretrizes e Bases da Educação Nacional (1996) exige a formação em nível superior em licenciatura plena para aqueles que vão atuar na educação básica e a Lei do Plano Nacional da Educação (2014) indica que os professores tenham a formação específica na área em que atuam.

A Lei n. ${ }^{\circ} 8.288$ (2012), no "Art.1 ${ }^{\circ}$. Torna obrigatória a construção de quadra poliesportiva nas escolas da rede municipal". Essas construções devem suprir as necessidades dos alunos e da comunidade local. Para Matos (2007, p. 3-4),

...uma escola sem quaisquer instalações esportivas pode contribuir para criar no imaginário do aluno um esquecimento e/ou desvalorização da Educação Física dentro da escola, como se não fizesse falta para sua formação... Caso o espaço físico escolar não atenda as necessidades do corpo discente, as aulas tendem a se tornar desmotivantes, acarretando uma fuga dos alunos, ou seja, buscam suprir suas inquietações motoras e afetivas em outros espaços.

A quadra representa um dos espaços das aulas de educação física na escola, componente curricular obrigatório da educação básica que, para uma parcela considerável da comunidade escolar, é a única 
oportunidade de vivência de práticas corporais para os alunos e usufruto do direito de cada um ao esporte. Daí, a importância de garantir a construção e manutenção de quadras nas instituições de ensino pois sem elas corre-se o risco de evasão escolar nos momentos destinados às aulas do componente curricular destinado à realização das práticas corporais.

No entanto, deve-se ponderar que nem tudo que é previsto em lei se concretiza. Dessa forma, é preciso considerar a distinção existente entre legislação e realidade, pois há situações em que os alunos utilizam espaços precários - quando há - para a realização dessas aulas, dificultando o trabalho do profissional e limitando o desenvolvimento dos estudantes.

\section{Conclusões}

Este estudo teve como objetivo analisar a legislação que regulamenta o esporte e o lazer na cidade de Salvador publicada entre 2006 e 2016. Assim, foram encontradas 13 leis referentes ao tema, que foram organizadas em cinco categorias para análise e discussão.

Na primeira categoria, que esteve relacionada ao "Desenvolvimento e organização da cidade", o esporte e o lazer são tratados de forma mais genérica em diversos momentos: ao trazer a importância de prioridade na construção de espaços para esporte e lazer, ao indicar a necessidade da inclusão de atividades desportivas adaptadas nos planos de ensino das escolas e ao recomendar adequações necessárias para as construções de espaços para o lazer e de áreas que são priorizadas para tais atividades.

A segunda categoria tratou da "Organização estrutural da gestão municipal”. Nos dez anos analisados, as pastas de esporte e lazer sofreram quatro trocas de setor, sempre acompanhando outras pastas. Considerase, no entanto, que a importância reside na garantia do investimento público em si e é de grande valia que a população tome conhecimento da sua dimensão cidadã, para que se mobilizem a fim de incluírem o tema na agenda pública, tornando uma demanda legítima de recursos e políticas públicas que fomentem e promovam o desenvolvimento do esporte e do lazer na cidade.

$\mathrm{Na}$ categoria "Grandes eventos", foram trazidas leis que regularam o funcionamento da cidade durante os megaeventos desportivos internacionais que ocorreram em todo o Brasil, com alguns jogos sendo sediados em Salvador. Essas leis estão direcionadas à garantia do bom funcionamento dos eventos, desde questões de infraestrutura até isenção de impostos para os organismos responsáveis pela sua realização. Dessa forma, garante bem-estar a uma pequena parte da população, que são os pagantes e telespectadores do evento, bem como os turistas. Assim, fica uma grande conta a pagar para aqueles que vivem a cidade no seu dia a dia e têm direitos usurpados com desapropriações, trabalhos precários e temporários e carência em diversas áreas sociais em que os orçamentos poderiam ter sido aplicados.

Na categoria "Data comemorativa", foi encontrada apenas a lei que define o dia do esporte para o idoso. Muitas pessoas não sabem sequer da existência de tal lei, podendo ser considerada como uma legislação limitada a uma data, enquanto se fazem necessárias políticas permanentes que venham a valorizar ações de promoção do esporte durante todo o ano. Destaca-se ainda que o incentivo ao esporte deve ser destinado a outros grupos sociais como deficientes, crianças, jovens, mulheres, dentre outros.

$\mathrm{Na}$ categoria "Esporte educacional", foram encontradas as leis que tratam da importância das quadras nas escolas e da formação inicial do professor que ministra as aulas de educação física. Essas leis acabam relacionando o espaço e o conhecimento como fatores importantes que devem compor as aulas, buscando a valorização das práticas corporais na escola. Pondera-se nessa temática que elas só terão efetividade a partir da fiscalização, acompanhamento e reivindicação da comunidade escolar pelos seus direitos ao espaço e ao profissional que mediará o esporte e a educação para o lazer na escola.

Podemos considerar que algumas leis, de certa forma, estimulam o esporte e o lazer como exercício de cidadania, como as que preveem as construções de espaços públicos para essas práticas. Há, porém, aquelas 
que estão voltadas para o esporte e o lazer como mercadorias, como as que se relacionam aos grandes eventos que priorizam o espetáculo e retira direitos dos cidadãos locais, a fim de garantir o seu sucesso.

Após a discussão das leis pesquisadas, traz-se a sugestão de que os professores de educação física possam explorar a educação para o esporte e o lazer em seus campos de atuação, ao contribuir para a divulgação da legislação que regulamenta esses direitos na cidade e colaborar para que os cidadãos soteropolitanos possam cobrar o cumprimento dessas leis em favor do bem comum. A legislação deve garantir direitos para toda a população que vive na cidade e isso só será possível com a participação coletiva na construção de ordenamento legal referente aos seus direitos e como desafio estratégico do acompanhamento e fiscalização na implementação das políticas de esporte e lazer citadinos.

\section{REFERÊNCIAS}

Bracht, V. (2011). Sociologia crítica do esporte: uma introdução (4ª ed.). Ijuí, Brasil: Unijuí.

Constituição da República Federativa do Brasil de 1988 (1988). Diário Oficial da União. Brasília, Brasil: Casa Civil da Presidência da República. Recuperado em: http://www.planalto.gov.br/ccivil_03/constituicao/constituicaoco mpilado.htm.

Costa, G. (2013). Sediar megaeventos esportivos vale à pena?. O Social em Questão, 29, 159-178.

Depieri, A. dos S. (2000). Esportes na terceira idade. (Monografia) - Faculdade de Educação Física. Universidade Estadual de Campinas. Campinas, Brasil. Recuperado de: https://www.bibliotecadigital.unicamp.br/documen $\mathrm{t} /$ ?down $=000328741$

Gil, A. C. (2008). Métodos e técnicas de pesquisa social (6 $6^{\mathrm{a}}$ ed.). São Paulo, Brasil: Atlas.

Lei No 10.741 de 2003. Dispõe sobre o Estatuto do Idoso e dá outras providências. $1^{\circ}$ de dezembro de 2003. Diário Oficial da União. Brasília, Brasil: Casa Civil da Presidência da República. Recuperado em: http://www.planalt o.gov.br/ccivil_03/leis/2003/110.741.htm.

Lei $N^{\circ} 7.045$ de 2006. Dispõe sobre a criação de programa de atividades desportivas no âmbito dos estabelecimentos de ensino, no período de férias escolares. 31 de julho de 2006. Diário Oficial do Município. Salvador: Gabinete do Prefeito. Recuperado em: https://leismunicipais.com.br/a2/ba/s/salvador/lei-ordinaria/2006/705/7045/lei-o rdinaria-n-7045-2006-dispoe-sobre-a-criacao-de-programa-de-atividades-desportivas-no-ambito-dos-estabeleci mentos-de-ensino-no-periodo-de-ferias-escolares?q=7.045.

Lei No 7.656 de 2009. Estabelece normas para atuação do professor de Educação Física no município de salvador. 26 de junho de 2009. Diário Oficial do Município. Salvador: Gabinete do Prefeito. Recuperado em: https://leismunicipais.com.br/a2/ba/s/salvador/lei-ordinaria/2009/766/7656/lei-ordinaria-n-7656-2009 -estabelece-normas-para-atuacao-do-professor-de-educacao-fisica-no-municipio-de-salvador?q=7.656.

Lei No 7.720 de 2009. Dispõe sobre medidas a serem adotadas pelo município do salvador para a realização de competições relativas aos jogos olímpicos e paraolímpicos de 2016 e dá outras providências. 15 de setembro de 2009. Diário Oficial do Município. Salvador: Gabinete do Prefeito. Recuperado em: https://leismunicipais.com. $\mathrm{br} / \mathrm{a} 2 / \mathrm{ba} / \mathrm{s} / \mathrm{salvador} /$ lei-ordinaria/2009/772/7720/lei-ordinaria-n-7720-2009-dispoe-sobre-medidas-a-seremadotadas-pelo-municipio-do-salvador-para-a-realizacao-de-competicoes-relativas-aos-jogos-olimpicos-e-paraoli mpicos-de-2016-e-da-outras-providencias? $\mathrm{q}=7.720$

Lei No 7.721 de 2009. Concede isenção, por tempo determinado, dos tributos municipais à Fifa e às entidades vinculadas à organização e à realização da copa mundial da Fifa de 2014, relativamente aos serviços, patrimônio e operações diretamente afetados a esta finalidade. 15 de setembro de 2009. Diário Oficial do Município. Salvador: Gabinete do Prefeito. Recuperado em: https://leismunicipais.com.br/a2/ba/s/salvador/lei-ordinaria/2009/773 /7721/lei-ordinaria-n-7721-2009-concede-isencao-por-tempo-determinado-dos-tributos-municipais-a-fifa-e-a s-entidades-vinculadas-a-organizacao-e-a-realizacao-da-copa-mundial-da-fifa-de-2014-relativamente-aos-servic os-patrimonio-e-operacoes-diretamente-afetados-a-esta-finalidade? $\mathrm{q}=7.721$.

Lei No 7650 de 2009. Altera a denominação da Secretaria municipal da educação e cultura - Smec, para Secretaria municipal da educação, cultura, esporte e lazer - Secult, modifica a sua estrutura organizacional e dá outras 
providências. maio de 2009. Diário Oficial do Município. Salvador: Gabinete do Prefeito. Recuperado em: https: //leismunicipais.com.br/a2/ba/s/salvador/lei-ordinaria/2009/765/7650/lei-ordinaria-n-7650-2009-altera-adenominacao-da-secretaria-municipal-da-educacao-e-cultura-smec-para-secretaria-municipal-da-educacao-cult ura-esporte-e-lazer-secult-modifica-a-sua-estrutura-organizacional-e-da-outras-providencias?q $=7650$.

Lei No 8.288 de 2012. Dispõe sobre a obrigatoriedade de construção de quadra poliesportiva nas escolas da rede municipal. 16 de maio de 2012. Diário Oficial do Município. Salvador: Gabinete do Prefeito. Recuperado em: https://leismunicipais.com.br/a2/ba/s/salvador/lei-ordinaria/2012/829/8288/lei-ordinaria-n-8288-2012 -dispoe-sobre-a-obrigatoriedade-de-construcao-de-quadra-poliesportiva-nas-escolas-da-rede-municipal?q $=8.28$ 8.

Lei No 8.376 de 2012. Modifica a estrutura organizacional da prefeitura municipal de salvador - PMS e dá outras providências. 20 de dezembro de 2012. Diário Oficial do Município. Salvador: Gabinete do Prefeito. Recuperado em: https://leismunicipais.com.br/a2/ba/s/salvador/lei-ordinaria/2012/838/8376/lei-ordinaria-n-8376-2012 -modifica-a-estrutura-organizacional-da-prefeitura-municipal-do-salvador-e-da-outras-providencias? $\mathrm{q}=8.376$.

Lei No 8.725 de 2014. Modifica a estrutura organizacional da prefeitura municipal do salvador e dá outras providências. 29 de dezembro de 2014. Diário Oficial do Município. Salvador: Gabinete do Prefeito. Recuperado em: https://1 eismunicipais.com.br/a2/ba/s/salvador/lei-ordinaria/2014/873/8725/lei-ordinaria-n-8725-2014-modifica-aestrutura-organizacional-da-prefeitura-municipal-de-salvador-pms-e-da-outras-providencias? $\mathrm{q}=8.725$.

Lei $N^{\circ} 8.838$ de 2015. Institui o dia $1^{\circ}$ de outubro como o "Dia Municipal de Esporte para a Pessoa Idosa”. 21 de agosto de 2015. Diário Oficial do Município. Salvador: Gabinete do Prefeito. Recuperado em: https://leismunicipais.com.br/a2/ba/s/salvador/lei-ordinaria/2015/884/8838/lei-ordinaria-n-8838-2015 -institui-o-dia-1-de-outubro-como-o-dia-municipal-de-esporte-para-a-pessoa-idosa?q=8.838.

Lei No 9.069 de 2016. Dispõe sobre o Plano diretor de desenvolvimento urbano do município de salvador - PDDU 2016 e dá outras providências. 30 de junho de 2016. Diário Oficial do Município. Salvador: Gabinete do Prefeito. Recuperado em: https://leismunicipais.com.br/a2/ba/s/salvador/lei-ordinaria/2016/907/9069/lei-ordinarian-9069-2016-dispoe-sobre-o-plano-diretor-de-desenvolvimento-urbano-do-municipio-de-salvador-pddu-201 6-e-da-outras-providencias? $\mathrm{q}=9.069$.

Lei № 9.089 de 2016. Altera e acrescenta dispositivos à lei $n^{\circ} 7.720 / 2009$ (Ato olímpico municipal) e dá outras providências. 15 de julho de 2016. Diário Oficial do Município. Salvador: Gabinete do Prefeito. Recuperado em: https://leismunicipais.com.br/a2/ba/s/salvador/lei-ordinaria/2016/909/9089/lei-ordinaria-n-9089-2016 -altera-e-acrescenta-dispositivos-a-lei-n-7720-2009-ato-olimpico-municipal-e-da-outras-providencias?q=9.08 9.

Lei No 9.148 de 2016. Dispõe sobre o ordenamento do uso e da ocupação do solo do município de salvador e dá outras providências. 08 de setembro de 2016. Diário Oficial do Município. Salvador: Gabinete do Prefeito. Recuperado em: https://leismunicipais.com.br/a2/ba/s/salvador/lei-ordinaria/2016/915/9148/lei-ordinaria-n-9148-2016 -dispoe-sobre-o-ordenamento-do-uso-e-da-ocupacao-do-solo-do-municipio-de-salvador-e-da-outras-providenc ias? $\mathrm{q}=9.148$.

Lei No 9.186 de 2016. Modifica a estrutura organizacional da prefeitura municipal do salvador e dá outras providências. 29 de dezembro de 2016. Diário Oficial do Município. Salvador: Gabinete do Prefeito. Recuperado em: https://leismunicipais.com.br/a2/ba/s/salvador/lei-ordinaria/2016/919/9186/lei-ordinaria-n-9186-2016 -modifica-a-estrutura-organizacional-da-prefeitura-municipal-de-salvador-e-da-outras-providencias?q=9.186.

Lei No 9394 de 1996. Estabelece as diretrizes e bases da educação nacional. 20 de dezembro de 1996. Diário Oficial da União. Brasília, Brasil: Casa Civil da Presidência da República. Recuperado em: http://www.planalto.gov.b r/ccivil_03/Leis/L9394.htm

Lei No 13.005 de 2014. Aprova o Plano Nacional de Educação - PNE e dá outras providências. 25 de junho de 2014. Diário Oficial da União. Brasília, Brasil: Casa Civil da Presidência da República. Recuperado em: http://www. planalto.gov.br/ccivil_03/_ato2011-2014/2014/lei/113005.htm

Lei № 9.615 de 1998. Institui normas gerais sobre desporto e dá outras providências. 24 de março de 1998. Diário Oficial da União. Brasília, Brasil: Casa Civil da Presidência da República. Recuperado em: http://www.planalt o.gov.br/ccivil_03/leis/L9615consol.htm. 
Leiro, A. C. R., Rocha, L. C., da Costa, M. B. y Venturini, M. (2010). Politica, Esporte e Mídia Impressa. Salvador: EDUFBA.

Marcellino, N. C. (1996). Politicas públicas setoriais de lazer. o papel das prefeituras. Campinas, Brasil: Autores associados.

Marcellino, N.C. (2007a). Lazer e cultura: Algumas aproximações. In: Marcellino, N.C. (org.). Lazer e cultura. Campinas: Alínea.

Marcellino, N. C. (2007b). Lazer e Educação (12 ed.). Campinas, Brasil: Papirus.

Mascarenhas, F. (2005). Entre o ócio e o negócio: teses acerca da anatomia do lazer. (Tese de Doutorado) - Faculdade de Educação Física. Universidade Estadual de Campinas. Campinas, Brasil. Recuperado de: https://periodicos. sbu.unicamp.br/ojs/index.php/conexoes/article/view/8637949.

Mascarenhas, F. (2001). Lazer e trabalho: Liberdade ainda que tardia. Anais do Seminário o Lazer em debate. Belo Horizonte, Brasil: Imprensa Universitária/CELAR/DEF/UFMG.

Matos, M. da C. (2007). Espaço Físico Escolar: Objeto Indispensável Para a Educação Física? Anais do XI Encontro Fluminense de Educação Física Escolar. Rio de Janeiro, Brasil: EnFEFE. Recuperado de: http://cev.org.br/biblio teca/espaco-fisico-escolar-objeto-indispensavel-para-educacao-fisica/.

Melo, V. A. de y Alves Jr., E. de D. (2012). Introdução ao lazer (2ª ed.). Barueri, Brasil: Manole.

Minayo, M. C. de S. (2001). Pesquisa Social. Teoria, método e criatividade (18 \# ed.). Petrópolis, Brasil: Vozes.

Ministério do Esporte (2005). Politica Nacional do Esporte. Brasília, Brasil. Recuperado de: http://www.esporte.gov. br/arquivos/politicaNacional/politicaNacionalCompleto.pdf

Oliveira, H.L.G. y Leiro, A.C.R. (2016). Políticas públicas de esporte no Mercosul: governo eletrônico e cidadania. Movimento, 22(2), 539-554. Recuperado de: http://seer.ufrgs.br/Movimento/article/download/54562/37383

Salvador (2018). A câmara municipal de Salvador e sua história. Câmara Municipal de Salvador. Recuperado de: http ://www.cms.ba.gov.br/pagina.aspx?id=1\&tipo=1.

Santos, E. S. dos y Starepravo, F. A. (2018). Estrutura Político-Administrativa dos Governos Municipais do Piauí e Investimento no Esporte e no Lazer. LICERE, 21(4), 166-183. https://doi.org/10.35699/1981-3171.2018.1 935.

Silva, E.A.P.C., Oliveira, L.S., Silva, P.P.C., Araújo, B.M.R., Caminha, I.O. y Freitas, C.M.S.M. (2012). Sociedade, cultura e saúde: motivação na utilização de espaço público de lazer. Movimento, 18(01), 171-188. Recuperado de http://seer.ufrgs.br/Movimento/article/download/22560/17345

Tschoke, A. (2013). Espaços públicos de lazer, a escola e a educação física: conhecer para refletir. Anais do XVIII Congresso Brasileiro de Ciências do Esporte e V Congresso Internacional de Ciências do Esporte. Brasília, Brasil. Recuperado de: http://cbce.tempsite.ws/congressos/index.php/conbrace2013/5conice/paper/view/5639

\section{Notas}

1 A Câmara Municipal de Salvador é a primeira entre as capitais brasileiras e nasceu junto com a cidade, em 1549. Tornouse uma das câmaras mais importantes do Império Colonial Português nas Américas e, por isso, recebeu os mesmos privilégios que as principais câmaras de Portugal, a exemplo das cidades de Évora e do Porto (SALVADOR, 2018).

2 O órgão foi extinto em 2019 e incorporado ao Ministério da Cidadania, como Secretaria Especial do Esporte. 